\title{
The Voice of PhD Candidates and PhD Supervisors. A Qualitative Exploratory Study amongst PhD Candidates and Supervisors to Evaluate the Relational Aspects of PhD Supervision in the Netherlands
}

\author{
Marla Woolderink \\ Department of Clinical Epidemiology \\ and Medical technology Assessment \\ (KEMTA) Maastricht UMC+ / CAPHRI \\ School for Public Health \\ and Primary Care, \\ Maastricht, The Netherlands \\ m.woolderink@maastrichtuniversity.nl
}

\author{
Hannerieke van der Boom \\ School Office CAPHRI \\ School for Public Health \\ and Primary Care, \\ Maastricht, The Netherlands
}

h.vanderboom@maastrichtuniversity.nl

\author{
Katarina Putnik \\ Department of Social Medicine, \\ Maastricht University, CAPHRI \\ School for Public Health \\ and Primary Care, \\ Maastricht, The Netherlands \\ k.putnik@maastrichtuniversity.nl
}
Gonnie Klabbers
Department of Social Medicine, Maastricht University, CAPHRI School for Public Health and Primary Care, Maastricht, The Netherlands gklabbers@hotmail.com

\begin{abstract}
Material published as part of this publication, either on-line or in print, is copyrighted by the Informing Science Institute. Permission to make digital or paper copy of part or all of these works for personal or classroom use is granted without fee provided that the copies are not made or distributed for profit or commercial advantage AND that copies 1) bear this notice in full and 2) give the full citation on the first page. It is permissible to abstract these works so long as credit is given. To copy in all other cases or to republish or to post on a server or to redistribute to lists requires specific permission and payment of a fee. Contact Publisher@InformingScience.org to request redistribution permission.
\end{abstract}

$\mathrm{PhD}$ trajectories are important to universities, as these contribute to the increase in knowledge and output. Therefore, they aim to decrease the completion time and dropout.

This article reports on our survey amongst $\mathrm{PhD}$ candidates and supervisors of the Graduate School CAPHRI, Maastricht University, The Netherlands. We investigated interpersonal aspects of coaching and (implicit) assumptions on skills and competences.

Both groups consider personality, knowledge, skills, communication and coaching the major factors contributing to a successful $\mathrm{PhD}$ trajectory. $\mathrm{PhD}$ candidates consider responsiveness and respectful, good-quality feedback by supervisors important and suggest regular assessment of their performance. Supervisors consider flexibility, open- 
ness for feedback, taking initiative and being a team-player as good qualities for PhDs. Supervisors indicate struggling with offering support versus independence during different stages of the $\mathrm{PhD}$ trajectory.

The study shows that a good match between PhDs and supervisors is essential for a successful $\mathrm{PhD}$ trajectory, and we advise that both discuss and formally agree upon mutual expectations and responsibilities within the project. We advocate that Graduate Schools foster an open and safe learning environment, organise meetings where supervisors can share experiences to learn from one another, provide contacts for advice and support and involvement of HR during the selection process.

Keywords: Quality of $\mathrm{PhD}$ supervision, Hurdles and success factors related to $\mathrm{PhD}$ supervision, Supervision of $\mathrm{PhD}$ candidates, Exploratory qualitative study, Communication in $\mathrm{PhD}$ supervision

\section{Introduction}

Successful and timely $\mathrm{PhD}$ completion are becoming increasingly important to universities across the world. Due to increasing competition the academic world is trying to improve scientific output and their rank in international ranking systems (VSNU, 2014). Scientific output is a major contributing factor to determine rankings. Universities partly rely on the output of $\mathrm{PhD}$ candidates to achieve the best possible output and as a consequence improve their rank in the international ranking systems (van de Schoot, Yerkes, Mouw, \& Sonneveld, 2013).

The current economic climate puts additional pressure on the relationship between the PhD candidates and their supervisors. Because of the financial climate and the consequential cutbacks that Dutch Universities are currently facing, it is necessary that $\mathrm{PhD}$ candidates finish their trajectories in time, thereby delivering sufficient output. As monitored by the 'Association of Dutch Universities' (VSNU) between 2001 and 2009, the average duration of a PhD trajectory is five years, exceeding the standard four-year Dutch $\mathrm{PhD}$ contract length. A PhD trajectory refers to the complete process of admission for a $\mathrm{PhD}$ placement until completion in a public defense of the thesis and receiving the $\mathrm{PhD}$ degree. In the Netherlands, a standard $\mathrm{PhD}$ has a four-year full-time employment contract.

Most universities describe formal regulations and procedures with regards to $\mathrm{PhD}$ trajectories and supervision, including requirements regarding training and education of $\mathrm{PhDs}$, formal requirements and responsibilities of supervisors, the composition of the supervision team agreements concerning monitoring of the progress, requirements regarding the members of the assessment committee, etcetera. Notably, Anglo-Saxon universities are much more specific in describing supervisor and $\mathrm{PhD}$ candidate roles, and in addition to the formal requirements they often provide guidelines on good practices (universities of Canterbury, NZ, Auckland, NZ, Reading, UK, Imperial College London, UK). According to these guidelines supervisors should be accessible, provide timely feedback, of good quality and in a constructive way, align the activities of the members of the supervision team and ensure that their evaluation of the progress of the trajectory are communicated regularly to the $\mathrm{PhD}$ candidate, consequently contributing to a constructive and effective working relation. Supervisors and $\mathrm{PhD}$ candidates should discuss the type and extent of feedback and the kind and amount of assistance during various stages of the trajectory, personal circumstances (e.g., health or financial hardship) that may affect progress, and mutual expectations regarding supervision, exchange of feedback, and the way that problems or disagreements should be addressed. In some occasions (starting) supervisors can be obliged to attend meetings or seminars on $\mathrm{PhD}$ policies and the supervision process on a regular basis (Auckland, NZ). However, these requirements, guidelines and good practices have not sufficiently been explored in scientific research yet. 
For universities to keep producing as much scientific output as possible, $\mathrm{PhD}$ trajectories are important and thus requirements to obtain a $\mathrm{PhD}$ degree are high. Therefore, universities need to invest in their PhD candidates. PhD candidates use a variety of resources, such as training and supervision. Untimely completion or dropout leads to loss of this investment for the university (Feldon, Maher, \& Timmerman, 2010). High-quality supervision is hypothesised to be a success factor for timely $\mathrm{PhD}$ completion and for high quality scientific output (Spaulding \& RockinsonSzapkiw, 2012).There is some evidence on success factors for successful and timely completion of PhD trajectories (Gardner, 2009; Jiranek, 2010; Rodwell \& Neumann, 2008; Sonneveld, 2009). According to van de Schoot et al. (2013) explanations for variations in $\mathrm{PhD}$ completion rates can be generalized into three categories: 1) institutional or environmental characters, 2) the nature and quality of supervision, and 3) characteristics of the $\mathrm{PhD}$ candidate. The second and third categories touch upon aspects related to supervision. A vast body of literature has been written on how to (best) supervise a PhD candidate (Cryer, 1997; Delamont, Atkinson, \& Barry, 2004; Lee, 2008; Taylor \& Beasley, 2005; Wisker, 2012). However less evidence exists about the relational aspects of supervision and the relation between the $\mathrm{PhD}$ candidate and their supervisors. Studies have shown that motivational aspects (showing interest), content aspects (knowledge of the supervisor on the topic), and process-oriented aspects are deemed necessary for qualitatively good supervision (Delaney, 2008; Gill \& Burnard, 2008; Leonard, Metcalfe, Becker, \& Evand, 2006; Sinclair, 2004; Sonneveld, 2009; Willems, 2009). Existing studies focussing on the relational aspects of $\mathrm{PhD}$ supervision mainly reported outcomes from the $\mathrm{PhD}$ candidates' perspective. Some studies have focused on the $\mathrm{PhD}$ supervisors perspective (Bøgelund, 2015) and even fewer have multiple perspectives (Grant, 2005; Lee, 2008). Especially the studies of Lee (2008) and Grant (2005) give insight in both perspectives on $\mathrm{PhD}$ supervision, however authors already remark the emphasis lies on the $\mathrm{PhD}$ supervisors' perspective.

Preliminary study findings within a specific study setting (Graduate school CAPHRI, Maastricht University, The Netherlands) suggest that one of the most pronounced reasons for dropout is a personal mismatch between supervisors and $\mathrm{PhD}$ candidates (Graduate school CAPHRI, Maastricht University, The Netherlands). Supervision of high-quality, tailored to the PhD's individual needs is therefore an extremely important issue, of high interest on a general level for universities, but also for the success of individual $\mathrm{PhD}$ trajectories. Although a $\mathrm{PhD}$ trajectory is focused on performance and output on a specific academic topic, supervision quality and the relationship with the supervisor are considered to be amongst the most important issues for a $\mathrm{PhD}$ candidate and should, therefore, not be underestimated.

A complicating factor of the relationship between $\mathrm{PhD}$ candidates and their supervisors is that they do not enter the $\mathrm{PhD}$ trajectory as equals; their relationship is hierarchical by nature. The $\mathrm{PhD}$ candidate is (highly) dependent on his or her supervisor(s), which is reflected by a go/no-go verdict 10 months after the start of a PhD trajectory in the Netherlands and by the quality and speed of the feedback provided by supervisors. Moreover, important decisions, such as when to submit a manuscript to a journal or to the thesis assessment committee, are being made by supervisors, not by $\mathrm{PhD}$ candidates. This can cause feelings of dependency and uncertainty within a person, feelings that need to be acknowledged and handled carefully by supervisors. Supervisors, on the other hand, may also experience doubts and difficulties in their relationship with a $\mathrm{PhD}$ candidate, even if they have ample experience with supervision. Whereas new supervisors might experience a lack of supervision skills or experience, the more experienced ones might not always be aware of the increasing gap between their own knowledge, skills, and competences and the level of those in their candidates. Individual supervisor's skills, such as empathy, communication and coaching skills, are highly important for matching or mismatching with a $\mathrm{PhD}$ candidate (Delaney, 2008; Gill \& Burnard, 2008; Sinclair, 2004). 
Considering the above and considering the size of the $\mathrm{PhD}$ candidate population (about 8702 in 2010 in the Netherlands) (VSNU, 2011), the quality of supervision and relational aspects between $\mathrm{PhD}$ candidates and their supervisors that might affect the performance of both and the factors influencing progress and success timely and completion of $\mathrm{PhD}$ trajectories are worth investigating in more detail. In addition this study aims to investigate both perspectives of the $\mathrm{PhD}$ candidates and the $\mathrm{PhD}$ supervisor on the relational aspects of supervision and on the quality of supervision.

With the present study we aim to explore relational aspects by investigating the expectations, experiences, and opinions of $\mathrm{PhD}$ candidates and supervisors regarding each other's role, thereby focusing on positive and negative contributing aspects.

\section{Methods}

\section{Setting}

This study was carried out amongst $\mathrm{PhD}$ candidates and supervisors in the field of Medicine and Health Sciences within Graduate School CAPHRI, Faculty of Health, Medicine \& Life Sciences of Maastricht University, The Netherlands. In general, $\mathrm{PhD}$ candidates in these fields deliver a number of scientific articles published in international, peer reviewed journals, which are compiled in the doctorate's thesis, also including an introduction and general discussion.

\section{Design}

For both groups a web-based questionnaire with closed and open-ended questions was designed in SurveyMonkey (www.surveymonkey.com) and the data were collected online in 2011.

\section{Participants}

The source population included all of 317 CAPHRI's internal and external $\mathrm{PhD}$ candidates. Of this group 54 persons responded $(17 \%)$. The source population of $\mathrm{PhD}$ supervisors contained in total 240 supervisors of which 52 responded $(22 \%)$.

\section{Procedure}

Firstly, announcement of the research was sent to all internal and external $\mathrm{PhD}$ candidates via email by the School's PhD co-ordinator and afterwards by the $\mathrm{PhD}$ coordinators via the monthly $\mathrm{PhD}$ information e-mail one month prior to opening of the survey. Secondly, three reminders were sent to increase response rate. Supervisors also received an invitation via e-mail by the $\mathrm{PhD}$ co-ordinator. The supervisors received two reminders. For both groups anonymity was guaranteed; participants did not have to leave their names or birth dates. In addition the surveys that were received were coded with an anonymous ID number so tracing a survey back to the actual respondent was impossible.

\section{Measures}

Two separate web-based questionnaires were constructed, one for the $\mathrm{PhD}$ candidates and one for $\mathrm{PhD}$ supervisors. We developed the questions based on the literature as well as our experience of working with $\mathrm{PhD}$ candidates. Amongst the authors three were $\mathrm{PhD}$ representatives, and one was a $\mathrm{PhD}$ coordinator for a number of years. The questionnaires were developed after thorough discussion amongst the authors of this article and in cooperation with the members of CAPHRI's Board of Education ( $\mathrm{PhD}$ representatives, $\mathrm{PhD}$ co-ordinator, confidential advisor for $\mathrm{PhD}$ candidates and the scientific director). The questionnaires were developed in English. 
The questionnaire for the $\mathrm{PhD}$ candidates started with two questions concerning the year of their $\mathrm{PhD}$ trajectory and the number of supervisors involved in their $\mathrm{PhD}$ trajectory, followed by seven open-ended questions. These questions were the following: what do $\mathrm{PhD}$ candidates value in their supervisor(s) and what do supervisors do to encourage them in their work; what would PhD can-

didates need from their supervisors for further stimulation and encouragement (one item about the daily supervisor and one about other supervisors); what difficulties do $\mathrm{PhD}$ candidates encounter related to supervision; if and how they overcame these difficulties; and further feedback regarding supervision.

In analogy, the supervisors' questionnaire started with two questions on the number of years they had been supervising and the number of $\mathrm{PhD}$ candidates currently under their supervision, followed by five open-ended questions: what competences do they themselves have that are necessary/beneficial for a successful $\mathrm{PhD}$ trajectory (in terms of publications and/or timely completion of the $\mathrm{PhD}$ ); what skills/competences of the $\mathrm{PhD}$ candidates do they value the most; what attributes of PhD candidates hamper a successful trajectory; what difficulties did they encounter in supervising PhD candidates; and how did they overcome these difficulties.

\section{Analysis}

The qualitative data was analysed using the principles of thematic analysis. Thematic analysis is an accessible and flexible approach to qualitative data analysis, which is based on coding (Braun $\&$ Clarke, 2006). Coding refers to categorising data, that is, labelling parts of text to a certain category (Joffe \& Yardley, 2004). Coding can be both deductive (researcher brings in codes to the data) or inductive (arising from the data). In this study we first proceeded with deductive coding. The codes were created for each question separately for $\mathrm{PhD}$ candidates and supervisors. Based on these codes mind maps were constructed which helped us cluster codes into themes. This represented inductive coding, as it was driven by the data. These steps were undertaken by authors HB and KP for the supervisors and by MW and GK for the PhD candidates, initially on an individual basis, and then integrated after deliberation with each other (inter-rater reliability).

\section{Results}

After extensive thematic analyses the open-ended questions resulted in the distinction of three main themes relevant for supervision process for both groups. These themes were the following:

Personality includes $\mathrm{PhD}$ candidates' characteristics such as perfectionism, self-esteem, and diligence, and supervisors' characteristics such as empathy, patience, and flexibility. It also concerns the relationship between the $\mathrm{PhD}$ candidate and his/her supervisor and addresses issues such as involvement and being a team player.

Knowledge and skills refer to the statements about $\mathrm{PhD}$ candidates being expected to increase their knowledge on the content and to improve writing skills and analytical skills, and supervisors being expected to have a solid knowledge of the topic, an extensive network, and methodological expertise.

Communication and coaching reflect the process of supervision and address, for instance, the way feedback is provided, whether the $\mathrm{PhD}$ candidate feels stimulated by his/her supervisors, and whether the schedule is monitored closely enough.

The results for the $\mathrm{PhD}$ candidates and the supervisors were analysed separately and are therefore presented separately too. Both sections start with a general part, followed by a specific part on problems related to the three emerging themes: Personality, Knowledge and skills, and Communication and coaching. 


\section{Results for PhD Candidates}

Of the responding $\mathrm{PhD}$ candidates, 52\% were in the second or third year of their $\mathrm{PhD}$ trajectory, $26 \%$ in their first year, $20 \%$ in their fourth year, and a minority started over four years ago. Most of these $\mathrm{PhD}$ candidates had two or three supervisors (81\%) and $9 \%$ of the respondents had more than three supervisors.

In general, $\mathrm{PhD}$ candidates stressed the importance of supervision and of the quality of the supervision for their performance. $\mathrm{PhD}$ candidates also suggested that the supervisors should be assessed on performance factors such as number of successful PhDs, number of timely graduated $\mathrm{PhD}$ candidates, delay in work of $\mathrm{PhD}$ candidates, and so on. Some even went as far as suggesting these performance factors should influence the supervisor's budget. $\mathrm{PhD}$ candidates indicated that performance factors and other factors related to good supervision should be written into a supervision guideline:

"It would be very good if there was a course for supervisors. Supervisors sometimes have a blind spot when it comes to supervision and so a course would be beneficial for all parties." $\mathrm{PhD}$ candidate \# 25

"I think there should be some clear guidelines for supervisors regarding what they should and are expected to do, and what they should avoid doing." PhD candidate \# 8

A general issue shown by the data is that $\mathrm{PhD}$ candidates complied with excessive workload by structurally working more than 40 hours a week. Some of them reported changing their own attitudes or mind-set in order to deal with the problems encountered. A few even ignored the problems, hoping they would go away after trying to solve them without success.

\section{Personality}

The $\mathrm{PhD}$ candidates reflected on the personality of their supervisor(s) by identifying valuable supervisors' characteristics for their motivation and encouragement.

The candidates specifically stated that what they wanted and needed from their supervisors included flexibility, honesty, being a good listener, and being empathic in order to be encouraged in their work. Empathy not only meant that supervisors should be able to understand the PhD candidate in work-related situations, but also in private situations, shifting from a role of a supervisor to the role of a mentor. Moreover, the supervisor showing explicit engagement and involvement in the project, but also taking an interest in the $\mathrm{PhD}$ candidate as a person and in his/her private life influenced the majority of the $\mathrm{PhD}$ candidates' work in a positive way:

"I value that my supervisor is personally very engaged in my project. She motivates me and that gives me peace and rest in very busy periods." $\mathrm{PhD}$ candidate \# 17

"She is always honest. You can tell her every problem you have and she will help you find a solution. She listens to your problems..." $\mathrm{PhD}$ candidate \# 8

Some but not all of the supervisors were considered inspiring and very successful in motivating, stimulating, and encouraging their $\mathrm{PhD}$ candidates. Not feeling inspired or motivated was considered detrimental to the $\mathrm{PhD}$ trajectory. In addition, $\mathrm{PhD}$ candidates wished to be more appreciated and trusted by a supervisor. Responsiveness was also considered to be a quality of supervisors that was highly valued, but often lacking. Some $\mathrm{PhD}$ candidates explained that they missed the responsiveness in their supervisors:

“A bit more interest in the work being done." $\mathrm{PhD}$ candidate \# 39

On trust, one candidate said, "I would need my supervisor to have faith in my abilities." $\mathrm{PhD}$ candidate \# 21 
According to the above, $\mathrm{PhD}$ candidates' motivation depended on a supervisor being empathic, taking an interest in the candidate, being open, being a good listener, and being responsive. A lack of these characteristics negatively influenced their motivation.

\section{Knowledge and skills}

$\mathrm{PhD}$ candidates stressed the importance of supervisors providing good content-related feedback and having a high level of content-expertise. Good content-related feedback was defined in terms of being clear, to the point, and providing unambiguous suggestions for improvement.

"[My supervisor has] high expertise, real interest in my work, gives very technical and detailed reviews of my work, has good attitude. [S/he] gives very detailed review of my drafts..." PhD candidate \# 21

"My supervisor is almost always available to answer my questions and is very patient explaining things. He has a lot of knowledge on the subject." PhD candidate \# 12

Not all $\mathrm{PhD}$ candidates were satisfied with the feedback provided by their supervisors. They reported needing better content-related feedback and clearer guidance. Improvement in the feedback also included a thorough preparation by the supervisor.

"[I need] more content driven instead of vague and general feedback. Teach me something instead of talking very general." PhD candidate \# 6

"[I need more] involvement and don't need them to only read the articles and change words, I need them to actually come up with new concepts or input." PhD candidate \# 25

$\mathrm{PhD}$ candidates clearly needed proper content-related feedback in order to help them improve the quality of their work. A high level of expertise was listed a prerequisite for good content related feedback.

\section{Communication and coaching}

Communication and coaching skills were much appreciated by $\mathrm{PhD}$ candidates. Firstly, $\mathrm{PhD}$ candidates found it important to have a good relationship with their supervisors individually, but also with the complete $\mathrm{PhD}$ team. Secondly, $\mathrm{PhD}$ candidates found it essential that supervisors take the feedback rules into consideration. What $\mathrm{PhD}$ candidates valued was feedback given in a nonjudgmental and constructive way, not just emphasising all that was not good. As long as feedback was constructive, it was evaluated positively by $\mathrm{PhD}$ candidates:

"Both supervisors are very involved in the research project. [I value their] involvement and the positive feedback they give me is encouraging." $\mathrm{PhD}$ candidate \# 4

"They encourage me by giving compliments when a job is done properly." $\mathrm{PhD}$ candidate \# 23

If supervisors showed involvement and provided $\mathrm{PhD}$ candidates direction, but at the same time offered sufficient freedom in their work, this encouraged the $\mathrm{PhD}$ candidate's confidence to proceed. One PhD candidate explained it as follows:

"The supervisor is helping me in finding my own way and research style." PhD candidate \# 24

"[I appreciate that my supervisor] comes up with new ideas, sets deadlines and helps me arrange certain things to achieve goals." PhD candidate \# 38 
$\mathrm{PhD}$ candidates found it important that their supervisors were available (for questions and advice via Email and/or an appointment), responded in time, set deadlines, and gave practical advice. They found it difficult to work when these coaching skills were missing:

"I need my daily supervisor to support me in the parts of the project that I have no experience with (e.g., planning a pilot-study, planning a project). I expect my daily supervisor to take the lead sometimes and not always wait for me to solve problems or address issues." $\mathrm{PhD}$ candidate \# 29

Some $\mathrm{PhD}$ candidates reported the supervisors having too high workload and working under a lot of pressure. This affected feedback and meetings:

"Due to stress and huge workload... feedback and meetings are rushed or vague." $\mathrm{PhD}$ candidate \# 10

On few occasions personal disagreements between supervisors, and supervisors having different opinions about the content of the $\mathrm{PhD}$ track were mentioned as problematic. At times, larger-scale departmental conflicts, in which supervisors were involved, affected the $\mathrm{PhD}$ project or $\mathrm{PhD}$ candidate as well:

"My supervisors have issues with each other." $\mathrm{PhD}$ candidate \# 35

"[I have difficulties with] departmental or even higher degree conflicts (with or together with the supervisors) affecting the workplace of a $\mathrm{PhD}$ candidate in a negative way." $\mathrm{PhD}$ candidate \# 45

Most $\mathrm{PhD}$ candidates stressed that talking with peers and colleagues, as well as direct communication with the supervisor, was the first step in the process of solving difficulties:

"[We solved it] mostly by negotiations." PhD candidate \# 10

"Working on the problem with people who are concerned with this problem." $\mathrm{PhD}$ candidate \# 22

In addition, they also tried to develop a better relationship with supervisor(s) and make arrangements and clear plans.

From the above it follows that good coaching skills, including providing constructive delivery of feedback, taking the lead when necessary, and providing a clear direction were considered extremely important by the $\mathrm{PhD}$ candidates. Communication, also among supervisors, was deemed necessary and helped to overcome difficulties or solve problems, though not on all occasions. A high workload was generally handled by working structural overtime, instead of communicating about it. It appears that $\mathrm{PhD}$ candidates considered a high workload as their own problem, instead of a joint problem.

\section{Results for PhD Supervisors}

The number of $\mathrm{PhD}$ candidates that supervisors guided varied: $76 \%$ reported supervising up to 6 $\mathrm{PhD}$ candidates, but also a considerable part (16\%) supervised more than $10 \mathrm{PhD}$ candidates, either as a co-promoter or as promoter. The respondents were generally equally divided on a continuum from relatively little experience to very experienced: almost a quarter $(23 \%)$ just started supervising, a quarter had 3 to 5 years of experience, $24 \%$ had 6 to 10 years of experience, and $28 \%$ had more than 10 years of experience as a $\mathrm{PhD}$ supervisor.

From the qualities that supervisors valued in themselves and in their $\mathrm{PhD}$ candidates that contribute to successful completion of the $\mathrm{PhD}$ trajectory, the difficulties they encountered and the ways in which they acted to overcome these, the same three themes as from the responses of the $\mathrm{PhD}$ candidates could be derived: personality, knowledge and skills, and communication and coaching. 


\section{Personality}

Personality characteristics related to one's own qualities as a supervisor that are perceived as helpful for the supervision process are flexibility, analytical thinking, empathy, social competences, being a team player, patience, insightfulness, ability to self-reflect, and being a good listener.

"Being aware of one's own supervision style and being able to vary the supervision style... and being able to shift the focus from professional to personal if needed." Supervisor \# 20

"Being patient, having expertise, coaching competencies... being a team worker and able to make decisions if necessary." Supervisor \# 7

Personality characteristics that supervisors highly valued in their $\mathrm{PhD}$-candidates were related to the ability to work in a team, while at the same time also being able to work independently and autonomously. Openness for receiving feedback and criticism, self-reflection, and enthusiasm were also considered important in $\mathrm{PhD}$ candidates.

“...it is very important that $\mathrm{PhD}$ candidates are able to reflect on their own functioning... so that they are able to ask for help at the right moment, to articulate their needs, to take critique and integrate feedback in their work." Supervisor \# 2

"Enthusiasm, positive outlook, independence, eagerness..." Supervisor \# 46

"Being transparent in why he or she has good or bad days, the candidate has selfreflection, and realizes in time that a thesis project is, or is not, the right choice for him or her." Supervisor \# 12

Two personality types in the $\mathrm{PhD}$ candidates were distinguished that might hamper the supervision process and the completion of the $\mathrm{PhD}$ trajectory. One type concerned candidates being too independent, overconfident, not being open for criticism, and having troubles accepting authority and expertise of the supervisor. The other type concerned candidates who were too dependent, passive, waiting for solutions offered, and had no self-confidence.

"Be too independent, do not ask for help timely; or the other way around, ask too much help" Supervisor \# 9

"...PhD not accepting (consciously or unconsciously) that supervisor might have superior knowledge and experience." Supervisor \# 36

The $\mathrm{PhD}$ candidate being sloppy or being too perfectionist was not appreciated either:

"Perfectionism, not being able to set priorities, postponing tasks." Supervisor \# 47

"Being sloppy and very slow with addressing feedback." Supervisor \# 49

Other characteristics that were identified by supervisors as difficult included rigidity, inflexibility, difficulties in dealing with stress and frustration, and a lack or loss of motivation.

\section{Knowledge and skills}

When reflecting upon their own qualities contributing positively to the supervision process knowledge of numerous specific methodologies, of statistics, and on the contents of the topic were mentioned, along with having an extensive network, experience in writing scientific papers, and previous experience in guiding research projects. One supervisor explained:

"I have ample experience in different methodologies, and based on that I can coach the $\mathrm{PhD}$ candidate where opportunities and difficulties lie during the PhD track." Supervisor \# 23 
When reflecting upon preferred skills of their $\mathrm{PhD}$ candidates, supervisors mentioned analytical skills, statistical knowledge, overview of the research topic, good networking, writing skills, and creativity.

"Organising skills, writing skills, communication skills, time planning skills, skill to discriminate." Supervisor \# 1

"Good writing skills, working in a structured way, good analytical skills..." Supervisor \# 18

However, sometimes the preferred qualities were lacking. For example, supervisors mentioned problems with their $\mathrm{PhD}$ candidate's English writing skills, analytical skills, and learning ability. More specifically, problems were mentioned in case of a lack of statistical and research methods skills.

"Not able to write a research plan or not able to translate research question in sub questions that are feasible to execute; not able to organise his or her own research and data collection; no writing skills." Supervisor \# 44

"Difficulties when a PhD candidate has problems with writing an article." Supervisor \# 41

Strategies to handle these problems included advising PhD candidates to attend courses, providing access to their own network, re-writing sections of articles, or trying out different writing methods that would suit the candidate better. Some supervisors decided on taking a course themselves, thereby improving their own supervisory skills. However, not all difficulties could be resolved by these strategies. The workload was sometimes considered too high since some supervisors had too many $\mathrm{PhD}$ candidates, which in their view compromised the supervision quality. This problem was considered unsolvable:

"It is difficult to overcome this issue, since it is not done to give PhDs to somebody else. Also, of course because somebody else may not have the expertise." Supervisor \# 27

Generally, PhD candidates and supervisors had the same opinions about necessary skills and competences for supervisors, concerning mainly expertise and experience. In case of lacking or insufficient skills more coaching was considered necessary.

\section{Communication and coaching}

Communication and coaching aspects that were considered important for the $\mathrm{PhD}$ trajectory concerned motivation, availability, support, expectations, and the personal relationship between the supervisor and the $\mathrm{PhD}$ candidate. Supervisors highlighted that their ability to motivate their $\mathrm{PhD}$ candidates and make them enthusiastic about the research was also brought about by their own dedication to the project.

"Inspiring young researchers concerning research, especially applied science and pragmatic studies, passion for research, creating an egalitarian climate where the candidate is stimulated to take responsibilities..." Supervisor \# 12

"Easy access both on- and off-line (just come to my office) creating a safe environment in which all suggestions/comments can freely be discussed without judgement." Supervisor \# 5

"I create a safe learning environment and connect candidates with similar themes to enhance creativity... I create challenging experiences with safe environment, so they are able to experience success." Supervisor \# 32 
Supervisors also tried to help the $\mathrm{PhD}$ candidates deal with (occasional) complexities that arise during team meetings. One supervisor highlighted:

"In joint meetings with the whole promotion team ( $\mathrm{PhD}$ candidate, co- and promoter(s)) I further notice that a $\mathrm{PhD}$ candidate cannot always process all information and questions directly. Therefore, I, as co-promoter, sometimes have (if $\mathrm{PhD}$ students asks for it) a talk afterwards, in which we go through everything and work out a concrete step-wise plan. I do think this especially occurs in the beginning of a PhD trajectory (year one and two)." Supervisor \# 17

Issues that supervisors considered problematic to deal with were lack of motivation and lack of organisational and communication skills in their $\mathrm{PhD}$ candidates.

"Nine to five mentality, unrealistic optimism, bad time-management, stubbornness." Supervisor \# 10

"Mixing private life with professional life, time management, lack of motivation to work after working hours." Supervisor \# 13

"Not doing what has been agreed upon." Supervisor \# 8

Supervisors also expected that, over time, $\mathrm{PhD}$ candidates would take more initiative in and responsibility over their project, and found it problematic if such transition did not take place. They also acknowledged that balancing independence of the $\mathrm{PhD}$ candidate and guidance by the supervisor is difficult. Expectations are pivotal in this, yet not circumscribed.

"If $\mathrm{PhD}$ candidates are not slowly developing more insight and responsibility of their project (in cooperation with the $\mathrm{PhD}$ team)." Supervisor \# 16

"Balance between telling the $\mathrm{PhD}$ candidate what to do, and allowing him/her to develop own ideas." Supervisor \# 25

Strategies by supervisors to handle these difficulties included making explicit and clear agreements, and being more responsive to the $\mathrm{PhD}$ candidates' needs.

"Stay clear to the candidate, make fixed appointments and when nothing works, stop the process." Supervisor \# 30

"I am busy, helpful: reflecting on it and working together with co-supervisors and assessing what works." Supervisor \# 20

Some supervisors interpreted the issues mentioned above in light of the learning process that a $\mathrm{PhD}$ candidate goes through and discussed the impact of a $\mathrm{PhD}$ trajectory on the future career of the candidate.

"Try to regard the $\mathrm{PhD}$ trajectory as a learning trajectory. Have attention for the career of your $\mathrm{PhD}$ candidate, he/she is not just doing research for you/with you, but also developing a career..." Supervisor \# 31

“...show $\mathrm{PhD}$ candidates all facets of doing a $\mathrm{PhD}$ so that they are prepared and able to continue research when they are done, and take the time to plan the future, what to do after $\mathrm{PhD}$ is finished." Supervisor \# 22

The interpersonal relationship between supervisors and their candidates deserves special consideration here. Loss of trust in each other or a mismatch on a personal level were perceived as a source of stress and frustration. Supervisors also mentioned difficulties in dealing with $\mathrm{PhD}$ candidates who had personal problems that affected their work capacity negatively. Sometimes the supervision team did not function well, such as different supervisors steering in divergent direc- 
tions, different views within the team, and not having good interpersonal relations within the supervision team:

"[I encounter problems regarding]...Different views within the inner circle on supervision; occasionally time shortage and political stuff (best left out of students' work)." Supervisor \# 22

"Unclear communication about cooperation in supervisors group and authorship, different supervisors who steer in different directions, or in different ways asking too much supervision from too many persons no penalties-consequences when students do not meet deadlines." Supervisor \# 34

Finally, supervisors also mentioned some procedural issues, such as lack of funding and the difficulty in guiding external $\mathrm{PhDs}$ who were physically far away.

Supervisors were quite clear about their own input in the coaching process. What supervisors struggled with was the amount and type of support needed in the different stages of the $\mathrm{PhD}$ trajectory and finding the right balance between delivering input and allowing the $\mathrm{PhD}$ candidate the freedom to decide for himself. Also the personal relationship between supervisor and $\mathrm{PhD}$ candidate sometimes gave rise to problems, which were handled by making clear agreements with the candidate, being responsive, and acknowledging the fact that a $\mathrm{PhD}$ trajectory is about learning and development. An overview of the concepts mentioned by both $\mathrm{PhD}$ candidates and $\mathrm{PhD}$ supervisors is presented in Figure 1.

Figure 1 is a visual representation of the most often reoccurring concepts mentioned by the interviewees. The figure shows the results of both supervisors and $\mathrm{PhD}$ candidates. Vertically the two groups are represented; $\mathrm{PhD}$ candidates on the left and $\mathrm{PhD}$ supervisors on the right. Horizontally the themes discussed are displayed. Analyses of the data showed $\mathrm{PhD}$ candidates reflect on their supervisors qualities and skills (success factors and hurdles) represented in the lower left quadrant. $\mathrm{PhD}$ candidates did not reflect on their own qualities and skills. This explains why the upper right quadrant of the figure is blank, meaning we did not evaluate this. For supervisors it is slightly different, they reflected on qualities and skills of their $\mathrm{PhD}$ candidates (success factors and hurdles) and they also reflected on their own qualities and skills which make their supervision successful (success factors). However PhD supervisors did not reflect on accepted or perceived hurdles. That is why half of the lower right quadrant is blank. 


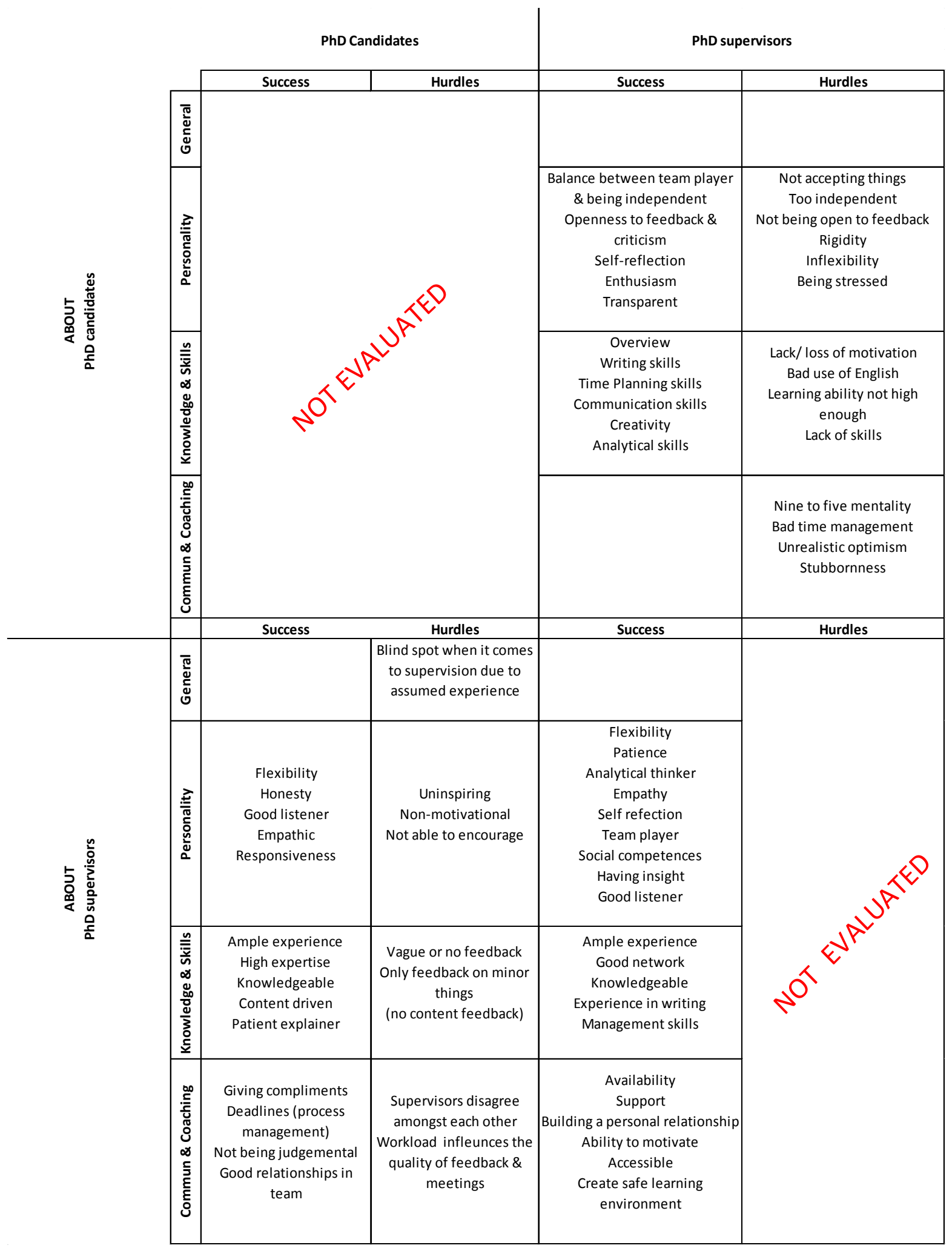

Figure 1: Overview of the concepts mentioned by both $\mathrm{PhD}$ candidates and $\mathrm{PhD}$ supervisors 


\section{Discussion}

We set out to examine the intricate relationship between $\mathrm{PhD}$ candidates and their supervisors and the hurdles and success factors related to good $\mathrm{PhD}$ supervision. By specifically focussing on what the individuals from both groups value in each other, this study contributes to an increased understanding of the needs of both $\mathrm{PhD}$ candidates and $\mathrm{PhD}$ supervisors. Practical solutions were suggested by both parties in case problems arose with $\mathrm{PhD}$ supervision. The respondents acknowledged and confirmed the importance of receiving (for the $\mathrm{PhD}$ candidates) and providing (for the supervisors) high quality supervision. According to both groups, good quality supervision increases motivation, as well as keeping a good flow in the project and enhance the selfconfidence and professional development of the $\mathrm{PhD}$ candidate. Thus, the practical solutions and the specific needs and preferences as reported by the respondents described above, can be used to facilitate (timely) $\mathrm{PhD}$ completion.

On a personal level, $\mathrm{PhD}$ candidates' motivation depended on a supervisor being involved, empathic, open, a good listener, and responsive. When personal attention was lacking, it created motivational problems for the $\mathrm{PhD}$ candidate. Similarly, the supervisors mentioned flexibility, empathy, social competences, and responsiveness in themselves as positively contributing factors to the trajectory. They were aware that motivating $\mathrm{PhD}$ candidates, investing time, and providing emotional guidance and support were necessary qualities for providing good supervision. Concerning personal attention, supervisors also acknowledged that insight into the personality of the $\mathrm{PhD}$ candidate helped tailor the supervision to individual needs (for the overlap in and links between answers, see Figure 1). Attributes appreciated by the supervisors in their $\mathrm{PhD}$ candidates were independence and taking initiative but also being receptive to feedback. Difficulties encountered involved overconfident $\mathrm{PhD}$ candidates who did not acknowledge the supervisors' expertise on the one hand, and passive candidates who relied too heavily on the supervisor on the other hand. Sloppiness or being too perfectionist were not much appreciated.

Generally, $\mathrm{PhD}$ candidates and supervisors had the same opinions about necessary knowledge and skills for supervisors. These included expertise on the content, methodological skills, abundant experience in publishing, knowledge of statistical methods, and having an extensive network. In addition, the $\mathrm{PhD}$ candidates stressed the importance of providing good content-related feedback, which should be specific and provide a clear direction to the work in progress. Necessary knowledge and skills for PhD candidates, more or less expected to be present, were analytical skills, statistical knowledge, good networking and writing skills, and creativity. Not all these qualities were found in all candidates. Strategies supervisors used to overcome these gaps included advising on which courses to take, helping them with writing, and monitoring the process and progress frequently. Some supervisors took a course on supervision to improve the quality to prevent or deal with problems related to above-mentioned gaps and skills. It was recognised by supervisors that a $\mathrm{PhD}$ trajectory was a learning trajectory, i.e., a development should take place in the work and professional attitude of a $\mathrm{PhD}$ candidate. It was expected that over time $\mathrm{PhD}$ candidates would take more initiative in and responsibility over their project. While supervisors felt that on some occasions development was lagging behind, $\mathrm{PhD}$ candidates occasionally felt that their development was not recognised enough. The supervisors specifically expressed their struggle with coaching a candidate towards more independence and with knowing what can or cannot be expected of a person in a certain phase of the trajectory. The results did not reveal whether these expectations were communicated and discussed with each other. Therefore, to prevent problems there should be an open and safe learning environment so that if one of the parties fails with respect to the above-mentioned expectations, the other party can address it without fear or feeling insecure.

Both $\mathrm{PhD}$ candidates and supervisors agreed on the importance of good communication and coaching skills. $\mathrm{PhD}$ candidates valued good coaching skills, including receiving constructive 
feedback, supervisors taking the lead when necessary, and providing clear direction. Similarly, supervisors wanted to motivate the candidates and make them enthusiastic about their research by showing their own dedication, by being available, providing support, and creating the right atmosphere. Inspiring their candidates and making them feel passionate about their research were aims frequently mentioned. Communicating well also helped to overcome difficulties or solve problems. However, on some occasions communication failed: personal disagreements between supervisors, or disagreements about the work of the $\mathrm{PhD}$ candidate, as well as problems within the department were reported that hampered the progress of the trajectory. In case of the workload being too high, $\mathrm{PhD}$ candidates handled this by structurally working overtime and not by communicating about it. However, it is not clear from the findings whether they did not raise the subject at all or whether they tried to discuss it but were turned down. Some supervisors criticised the 'nine to five mentality' or the 'lack of motivation to work after working hours', so the authors suspect this is a sensitive issue to discuss.

In general, it is noteworthy to mention the nature of the relationship between the $\mathrm{PhD}$ candidate and the supervisor, which is based on a power difference. Hence, $\mathrm{PhD}$ candidates are bound to be affected more if the relationship is not good, than supervisors. We believe that $\mathrm{PhD}$ candidates are well-aware of the power difference in their relationship with supervisors. Consciously or subconsciously, the dependence on the supervisors' judgement, feedback, availability, and approval affects the trust in one-self and self-esteem and can cause insecurities that may vary from minor uncertainties that can easily be solved or discussed, to fundamental insecurities that can hamper daily functioning. Although supervisors may also be well-aware of this disparity in their mutual relation, they may not always be aware of the day-to-day effect it has on the state of mind and attitude of their $\mathrm{PhD}$ candidates and the level of insecurity and dependence it involves. In that light, direct and explicit communication, appreciation of mutual openness and trust, are all the more important.

\section{Recommendations}

Based on the results we propose several recommendations. Though some of these may not be 'new' that is they may already be a part of the guidelines or good practices in place at some universities, we feel that the current study results underpin and warrant the listing of these recommendations. In general, we consider it very important that mutual expectations and responsibilities should be explicitly discussed and put down in writing at the start of the $\mathrm{PhD}$ trajectory (van der Boom, Klabbers, Putnik, \& Woolderink, 2013). These mutual expectations and responsibilities should have a regular follow-up and readjustment. During yearly evaluation meetings, and preferably more often, not only the progress of the PhD trajectory should be discussed, but the relationship and communication within the $\mathrm{PhD}$ team should be appraised as well. Feedback on work in progress or performance, by either one of the parties, should be given in a constructive and respectful way, contributing to a positive and confidence-building atmosphere. $\mathrm{PhD}$ candidates are recommended to make a long-term, structured plan of meetings with their supervisors to ensure sufficient guidance, to take minutes of each meeting, and to take initiative and responsibility for the $\mathrm{PhD}$ trajectory and be open for feedback. Supervisors are recommended to involve the $\mathrm{HR}$ department in the selection of a PhD candidate, and seek advice and guidance in the form of supervision courses or regular peer exchange of supervision experiences, preferably facilitated by their organisation. Supervisors are recommended to tailor their supervision style and approach to the specific $\mathrm{PhD}$ candidate, and provide varying levels of support adjusted to the phase of the $\mathrm{PhD}$ trajectory and the needs of the individual, thereby fostering their confidence and selfesteem(van der Boom et al., 2013). We recommend that the supervision team consists of at least two, and maximum three or four supervisors who complement each other and that they clearly

divide their tasks. One should be made responsible and available for the more intense daily coaching of the candidate. The whole team should remain conscious of the dynamics within the 
supervising team and of the $\mathrm{PhD}$ trajectory and how this may affect the $\mathrm{PhD}$ candidate(van der Boom et al., 2013).

\section{Limitations}

Some limitations of the present study must be taken into account in order to correctly interpret the findings. Firstly, although the response rate was limited, the authors believe the responses were reflective of the variety of $\mathrm{PhD}$ candidates' and supervisors' experiences, considering that a lot of information received was centring repeatedly on the highlighted themes, indicating saturation. Secondly, authors cannot pair the responding $\mathrm{PhD}$ candidates with the responding supervisors considering that participation was anonymous. This would have been particularly interesting since it would have enabled us to study whether there are interpretational differences or strategic differences in recognising or dealing with problems. Thirdly, our questionnaire did not include $\mathrm{PhD}$ candidates having to reflect on their own attitudes, knowledge, or skills (as shown in Figure 1) whereas we asked the supervisors about their attributes contributing to a successful $\mathrm{PhD}$ trajectory. Given the finding that supervisors sometime struggled with personality attributes of the candidates it would have added to the findings if we knew how $\mathrm{PhD}$ candidates interpret the importance of their personality to the trajectory. Fourthly, difficulties and how to overcome these were topics included in separate questions. Therefore, we could not always relate the strategy to the problem. However, because a substantial part of the participants combined both questions, this enabled us to integrate them. Finally, the present study has been conducted within one graduate school and the question is whether the results are applicable to the same extent to other schools in and outside the Netherlands as well. However, considering this particular graduate school is quite large and encompasses numerous departments that vary in size and topic, we believe that this study can be of use to other $\mathrm{PhD}$ candidates and supervisors in other health-related academic settings as well.

\section{Conclusion}

This study contributes to an increased understanding of the needs, wants, preferences, and expectations of both $\mathrm{PhD}$ candidates and $\mathrm{PhD}$ supervisors regarding supervision. The study is unique in its kind due to the fact that it reflects on and describes perspectives of both the PhD candidate and their supervisor. Interesting to see is that there is an overlap between the answers given by both parties which means the same attributes are valued. This is a good starting point for an increased. understanding about each other's needs and might improve the relationship between the $\mathrm{PhD}$ candidate and the supervisors.

$\mathrm{PhD}$ candidates and their supervisors can save a lot of time and mishap when discussing mutual expectations and needs before and during the $\mathrm{PhD}$ trajectory. This might diminish the dropout rate as well as enhance timely completion of $\mathrm{PhD}$ trajectories without compromising the quality of scientific output. At the same time, costs can be saved on departmental and university level. Further research should seek to validate the results in other scientific fields, and in other countries.

\section{Acknowledgement:}

This manuscript is based on a study performed within graduate school CAPHRI, Maastricht University, the Netherlands. Based on the data, the authors have published a booklet for internal use and this manuscript builds on this earlier work. 


\section{References}

Bøgelund, P. (2015). How supervisors perceive $\mathrm{PhD}$ supervision - And how they practice it. International Journal of Doctoral Studies, 10, 39-55. Retrieved from http://ijds.org/Volume10/IJDSv10p039055Bogelund0714.pdf

Braun, V., \& Clarke, V. (2006). Using thematic analysis in psychology. Qualitative Research in Psychology, 3(2), 77-101.

Cryer, P. (1997). Handling common dilemmas in supervision. London.

Delamont, S., Atkinson, P., \& Barry, O. (2004). Supervision the doctorate: A guide to success. Maidenhead.

Delaney, D. (2008). A review of the literature on effective PhD supervision. Dublin: Center for Academic Practice and Student Learning CAPSL, Trinity College.

Feldon, D. F., Maher, M. A., \& Timmerman, B. E. (2010). Graduate education. Performance-based data in the study of STEM Ph.D. education. Science, 329(5989), 282-283. doi: 10.1126/science.1191269

Gardner, S. (2009). Student and faculty attributions of attrition in high and low completing doctoral programs in the United States. Higher Education, 58, 15.

Gill, P., \& Burnard, P. (2008). The student-supervisor relationship in the PhD/Doctoral process. British Journal of Nursing, 17(10), 668-672. doi: 10.12968/bjon.2008.17.10.29484

Grant, B. (2005). The pedagogy of graduate supervision: Figuring the relations between supervisor and student. Auckland: The University of Auckland.

Jiranek, V. (2010). Potential predictors of timely completion among dissertation research students at an Australian faculty of sciences. International Journal of Doctoral Studies, 5, 1-13. Retrieved from http://ijds.org/Volume5/IJDSv5p001-013Jiranek273.pdf

Joffe, H., \& Yardley, L. (2004). Content and thematic analysis. In M. D.F. \& L. Yardley (Eds.), Research methods for clinical and health psychology (pp. 56-68). London: Sage publications.

Lee, A. (2008). How are doctoral students supervised? Concepts of doctoral research supervision. Studies in Higher Education, 33(3), 14.

Leonard, D., Metcalfe, J., Becker, R., \& Evand, J. (2006). Review of literature on the impact of working context and support on the postgraduate research student learning experience. The Higher Education Academy.

Rodwell, J., \& Neumann, R. (2008). Predictors of timely doctoral student completions by type of attendance: the utility of a pragmatic approach. Journal of Higher Education Policy and Management, 30(1), 11 .

Sinclair, M. (2004). The pedagogy of 'good' PhD supervision: A national cross-disciplinary investigation into PhD supervision. Canberra, Australia: Department of Education, Science, and Training.

Sonneveld, H. (2009). Monitoring PhD supervision quality. The Dutch way. Netherlands Centre for Research Schools and Graduate Schools.

Spaulding, L. S., \& Rockinson-Szapkiw, A. J. (2012). Hearing their voices: Factors doctoral candidates attribute to their persistence. International Journal of Doctoral Studies, 7, 199-219. Retrieved from http://ijds.org/Volume7/IJDSv7p199-219Spaulding334.pdf

Taylor, S., \& Beasley, N. (2005). A handbook for doctoral supervisors. New York: Routledge.

van de Schoot, R., Yerkes, M. A., Mouw, J. M., \& Sonneveld, H. (2013). What took them so long? Explaining PhD delays among doctoral candidates. PLoS One, 8(7), e68839. doi: 10.1371/journal.pone.0068839 
van der Boom, H. C. I., Klabbers, G., Putnik, K., \& Woolderink, M. (2013). It takes two to tango. A qualitative study amongst PhD candidates and supervisors to evaluate the process of PhD supervision in the Netherlands. Maastricht: Canon.

VSNU. (2011). Jaaropgaven promovendi 2011., from http://www.vsnu.n1/Universiteiten/FeitenCijfers/Onderzoek.htm

VSNU. (2014). Gepromoveerde van belang voor Nederland. 2.

Willems, F. (2009). PhD candidates and career. How to guide young talented researchers through their PhD training and prepare them for a successful career path. Maastricht: Maastricht University

Wisker, G. (2012). The good supervisor- Supervising postgraduate and undergraduate research for doctoral thesis and graduation. (2nd ed. Vol. 2). New York: Palgrave Macmillan.

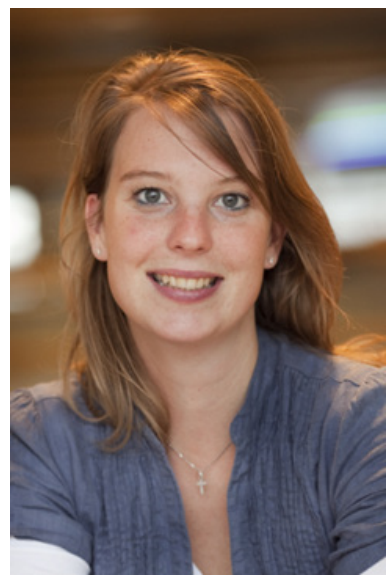

\section{Biographies}

Marla Woolderink, MSc, obtained her BSc in Health Organisation, Policy and Economics and has a degree from CAPHRI Health Research Master, with a specialisation in Epidemiology and Health Technology Assessment. She has been $\mathrm{PhD}$ representative for CAPHRI from July 2010 to December 2012. Marla started the PhD supervision project in 2011 and is currently the representative for the Netherlands School of Primary Care (CaRe). Currently Marla is working on costeffectiveness analyses of an online health prevention intervention.

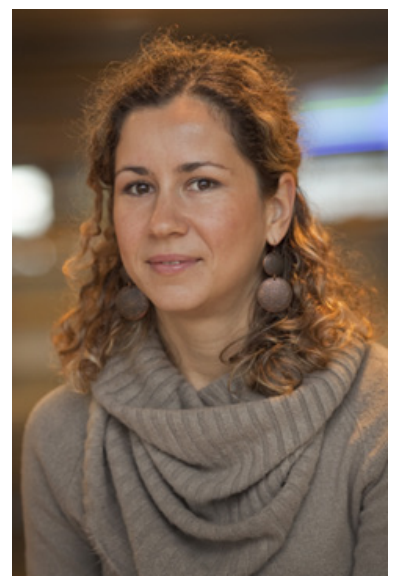

Katarina Putnik, MA; MSc, has a degree in Psychology from the University of Malta, an M.A. degree in Peace studies and conflict transformation from the European Peace University, Austria and an M.Sc. in Public Health with the specialisation in Work and Health from Maastricht University, the Netherlands. She is finalising her PhD on the topic of work-home interface across cultural contexts at the Social medicine and Epidemiology departments of Maastricht University, CAPHRI research school. Driven by a motivation to be engaged in the $\mathrm{PhD}$ issues that go beyond her own trajectory, Katarina has been chosen as the $\mathrm{PhD}$ representative for the CAPHRI research school from 2009-2011 and a $\mathrm{PhD}$ representative for the Netherlands School of Primary Care (CaRe) from 2012-2014. Currently, Katarina works as a research scientist on the topic of work innovations at TNO, Leiden, the Netherlands. 


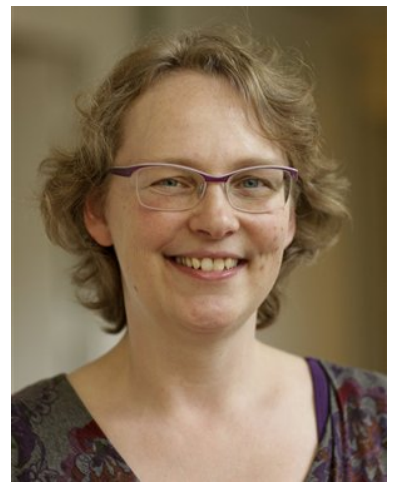

Hannerieke van der Boom, $\mathrm{PhD}$, has obtained her degree in Arts and Sciences at Maastricht University in 1997. During her PhD trajectory, she performed a comparative study on home nursing professionals and has been PhD representative for the School CAPHRI. After having obtained her PhD degree in 2008, she worked as a researcher and lecturer in Health Sciences and became CAPHRI's PhD co-ordinator. Since 2013, she is also working as policy advisor on PhD Affairs at the Faculty of Health, Medicine and Life Sciences at Maastricht University.

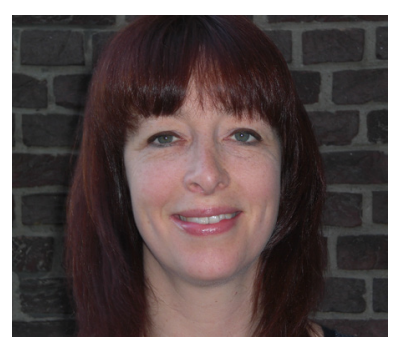

Gonnie Klabbers, $\mathrm{PhD}$, studied Health Sciences, Work \& Health at Maastricht University, Maastricht, The Netherlands and obtained her $\mathrm{PhD}$ degree on social health inequalities in 2012 at the same university. Besides research, she also worked as a lecturer in Health Sciences. During her $\mathrm{PhD}$ track she was a $\mathrm{PhD}$ representative in three $\mathrm{PhD}$ committees. After obtaining a $\mathrm{PhD}$, Gonnie Klabbers worked as a postdoc researcher for two years. 